\title{
Recognition memory in amnesia: Effects of relaxing response criteria
}

\author{
MIEKE VERFAELLIE and KELLY SULLIVAN GIOVANELLO \\ Boston VA Healthcare System, Boston, Massachusetts \\ and Boston University School of Medicine, Boston, Massachusetts \\ and \\ MARGARET M. KEANE \\ Boston VA Healthcare System, Boston, Massachusetts \\ Boston University School of Medicine, Boston, Massachusetts \\ and Wellesley College, Wellesley, Massachusetts
}

\begin{abstract}
In two experiments, using the remember/know paradigm, we examined whether recognition memory in amnesic patients can be improved by instructing patients to relax their response criterion. Experiment 1 was modeled after a study by Dorfman, Kihlstrom, Cork, and Misiaszek(1995), in which direct instructions to respond more leniently led to an increase in recognition accuracy in patients with ECT-induced amnesia. We failed to extend this finding to patients with global amnesia, but the manipulation was unsuccessful in control subjects as well. In Experiment 2, response criterion was manipulated indirectly by providing information about the alleged base rate of study items on the recognition test. This manipulation led to a criterion shift in control subjects and enhanced discriminability in amnesic patients. Analysis of "remember" and "know" responses suggests that improved accuracy in amnesia was associated with enhanced familiarity-basedrecognition.
\end{abstract}

Amnesic patients have a dense impairment in the conscious retrieval of recent experiences, a deficit that is revealed on explicit tasks of memory such as recall and recognition. However, several findings suggest that the processes underlying explicit memory may not be uniformly disrupted in amnesia. In a review of studies of recognition memory in amnesia, Aggleton and Shaw (1996) concluded that patients with selective limbic damage show a relative preservation of recognition in comparison with recall. They interpreted these findings in the context of dual-process models of recognition (Jacoby \& Dallas, 1981; Mandler, 1980) and proposed that amnesia disrupts recollection-based mechanisms, but leaves familiaritybased mechanisms relatively intact.

Researchers have used the process dissociation procedure (Verfaellie \& Treadwell, 1993) or the rememberknow paradigm (Knowlton \& Squire, 1995; Schacter, Verfaellie, \& Pradere, 1996) to examine the status of familiarity-based recognition in amnesia more directly. On the basis of a review of these studies, as well as their own data, Yonelinas and colleagues (Yonelinas, Kroll, Dobbins, Lazzara, \& Knight, 1998) concluded that although familiarity-based recognition is not intact in am-

This research was supported by NINDS Program Project Grant NS 26985 and NIMH Grant 57681 to Boston University and by the Medical Research Service of the VA Healthcare System. Correspondence should be addressed to M. Verfaellie, Memory Disorders Research Center, Boston VA Healthcare System (151A), 150 S. Huntington Ave., Boston, MA 02130 (e-mail: verf@bu.edu). nesia, the disruption in familiarity is consistently smaller than the disruption in recollection.

If amnesic patients have a relative preservation of familiarity-based recognition, the question arises whether conditions can be created that enhance amnesics' reliance on familiarity, thus boosting their recognition accuracy. Dorfman and colleagues (Dorfman, Kihlstrom, Cork, \& Misiaszek, 1995) reported that they had successfully enhanced the recognition performance of patients with ECT-induced amnesia by asking them to relax their response criterion. In a high-criterion condition, participants were told to endorse a test word only if they were relatively sure that it had appeared on the study list. In a low-criterion condition, they were told to endorse a test word if it seemed at all familiar. Control subjects endorsed more studied and unstudied words in the lowthan in the high-criterion condition, indicating a change in response bias. ECT patients, in contrast, endorsed more studied, but not unstudied, words in the low- than in the high-criterion condition, indicating a change in discriminability. These patients' enhanced recognition was attributed to the contribution of familiarity to performance in the low-criterion condition.

In two experiments, Reber and Squire (1999) attempted to extend these findings to patients with global amnesia by manipulating response criterion. In neither experiment did they find differences in amnesics' discriminability as a function of instructions. Even an exact replication of Dorfman et al.'s (1995) procedures was unsuccessful, but noteworthy was that the effect of the criterion manipula- 
tion in that experiment (Experiment 3 ) was only marginally significant in amnesic patients and was absent in the control subjects. Perhaps the experimental manipulation was not sufficiently powerful to allow for changes in patients' discriminability.

In light of this concern, and of the potential importance of a demonstration of improved discriminability in amnesia, we conducted the present study to again assess whether manipulating test instructions could enhance recognition memory in patients with global amnesia.

\section{EXPERIMENT 1}

In this experiment, we employed the same manipulation of response criterion that was used in previous studies (Dorfman et al., 1995; Reber \& Squire, 1999). Our first goal was to establish whether instructions to set a more lenient criterion would improve discriminability in patients with global amnesia. Our second goal was to evaluate the claim of Dorfman et al. (1995) that changes in discriminability were associated with enhanced familiarity-based recognition.

To obtain measures of the contribution of recollection and familiarity to performance, we asked participants to provide remember-know judgments (Gardiner, 1988; Tulving, 1985). On the assumption that recollection and familiarity serve as independent bases of recognition, "remember" $(\mathrm{R})$ responses provide a relatively pure measure of recollection, but "know" (K) responses underestimate familiarity because $\mathrm{R}$ and $\mathrm{K}$ responses are mutually exclusive. Consequently, $\mathrm{K}$ responses provide an estimate of familiarity only in the absence of recollection (Jacoby, Yonelinas, \& Jennings, 1997; Yonelinas et al., 1998). To correct for this, we used the independentremember/know (IRK) procedure (Jacoby et al., 1997; Yonelinas \& Jacoby, 1995) and divided the proportion of K responses by the proportion of items that were not assigned $\mathrm{R}$. We reasoned that if improvement in amnesics' recognition was due to the additional recruitment of familiarity-based processes, then enhanced discriminability should be associated with an increase in the measure of familiarity, as derived from the IRK procedure.

\section{Method}

Participants. Eighteen amnesic patients (13 males, 5 females) with an etiology of alcoholic Korsakoff's syndrome $(n=8)$, anoxia $(n=8)$, encephalitis $(n=1)$, or bithalamic stroke $(n=1)$ participated in the experiment. The amnesic group had a mean age of 60.9 years and a mean education of 13.8 years. Their intellectual functioning was in the average range, as indicated by a mean Verbal IQ score of 99.8 on the Wechsler Adult Intelligence Scale-Revised (WAIS-R; Wechsler, 1981). Their memory functioning was severely compromised: On the Wechsler Memory Scale-Revised (WMS-R; Wechsler, 1987), they obtained a mean General Memory index of 75.7 and a Delayed Recall index of 59. Attentional abilities, as measured by the WMS-R Attention-Concentration index, were average $(M=100.2)$.

The control group consisted of 8 individuals with a history of alcoholism ( 8 males) and 10 healthy adults without a history of alcoholism (5 males and 5 females). Alcoholic controls had abstained from alcohol for at least 1 month prior to participation in the experiment. The control group was matched to the amnesic patients in terms of age ( $M=59.1$ years), education $(M=14.1$ years), and WAIS-R Verbal IQ $(M=104.8)$.

Materials. One hundred twenty low-frequency nouns $(M=30.9)$ served as stimuli (Francis \& Kučera, 1982). Two lists were constructed, each consisting of two sets of 30 items matched for frequency. For each list, one of the two sets served as targets and the other set served as distractors for the recognition task. Assignment of lists to instruction conditions, as well as assignment of item sets as targets, was counterbalanced across participants.

Procedure. The participants were tested in two sessions separated by 1 week. Half of the participants received the high-criterion instructions and the other half received the low-criterion instructions during the first session.

During the study phase, the participants were told that they would be shown a list of words, one at a time. They were instructed to read the words aloud and to try to remember them for a subsequent memory test. Each word appeared for $2 \mathrm{sec}$, with a 1-sec interstimulus interval. There was a 10-min delay between the study and test phase.

During the test phase, the participants made yes/no recognition judgments on each word. In the high-criterion condition, they were instructed to say "yes" if they were fairly sure that the word had appeared on the study list and to say "no" if they were not sure. In the low-criterion condition, the participants were instructed to say "yes" if they thought they might have seen the word and to say "no" if the word was not familiar at all. Remember and know responses were collected for each endorsed item (Gardiner \& Parkin, 1990). The participants were instructed to respond "remember" if they could recollect specific details about a word's presentation, if it evoked a specif ic association or experience. They were instructed to respond "know" if they recognized the word, but could not recollect specific details. The instructions remained visible throughout the test phase.

\section{Results and Discussion}

The results of the alcoholic and nonalcoholic subgroups within the amnesic and control groups were combined because there were no significant differences as a function of alcohol history.

Overall recognition. Table 1 presents the proportion of studied and unstudied items endorsed as old by amnesic patients and control subjects in the high- and low-criterion conditions. As expected, control subjects endorsed considerably more studied items (hits) and somewhat fewer unstudied items (false alarms) than did amnesic patients. Instructions had little or no effect on the proportion of hits and false alarms in either group. An analysis of variance (ANOVA) of hit rates revealed a significant effect of group $[F(1,34)=16.1, p<.01]$, but no effect of instructions $[F(1,34)=1.97, p>.17]$ and no group $\times$ instructions interaction $(F<1)$. Analysis of false alarm rates revealed no significant effects (all $F_{\mathrm{s}}<2.17, p \mathrm{~s}>.15$ ). Analysis of discriminability scores measured by $d^{\prime}$ revealed a significant effect of group $[F(1,34)=16.1, p<.01]$. There was no effect of instructions and no group $\times$ instructions interaction (both $F_{\mathrm{S}}<1$ ).

Remember-know responses. The proportion of correct responses given by the amnesic patients and controls were subdivided into $\mathrm{R}$ and $\mathrm{K}$ responses. The data from one amnesic patient were eliminated from this analysis because he provided more $\mathrm{R}$ responses to unstudied words than to studied words, a finding suggesting that he did not understand the remember-know instructions. As 
Table 1

Proportion of Studied and Unstudied Words Endorsed as Old, and $d^{\prime}$ Scores, in the Different Criterion Conditions of Experiment 1

\begin{tabular}{|c|c|c|c|c|c|c|c|c|}
\hline & \multicolumn{2}{|c|}{ Overall } & \multicolumn{2}{|c|}{$\mathrm{R}$} & \multicolumn{2}{|c|}{$\mathrm{K}$} & \multicolumn{2}{|c|}{ IRK } \\
\hline & Amnesics & Controls & Amnesics & Controls & Amnesics & Controls & Amnesics & Controls \\
\hline \multicolumn{9}{|l|}{ Studied } \\
\hline High criterion & .46 & .72 & .17 & .44 & .29 & .29 & .38 & .48 \\
\hline Low criterion & .50 & .76 & .20 & .55 & .30 & .22 & .37 & .52 \\
\hline \multicolumn{9}{|l|}{ Unstudied } \\
\hline High criterion & .19 & .14 & .06 & .05 & .13 & .09 & .13 & .10 \\
\hline Low criterion & .21 & .14 & .06 & .04 & .15 & .11 & .15 & .12 \\
\hline \multicolumn{9}{|l|}{$d^{\prime}$} \\
\hline High criterion & .89 & 1.87 & .51 & 1.52 & & & .99 & 1.37 \\
\hline Low criterion & .94 & 2.00 & .65 & 1.85 & & & .91 & 1.49 \\
\hline
\end{tabular}

Note-Overall endorsement rates are broken down into $\mathrm{R}$ and $\mathrm{K}$ responses. $\mathrm{R}$ responses provide a measure of recollection. Familiarity estimates are based on IRK scores $(\mathrm{K} / 1-\mathrm{R})$ and provide a measure of familiaritybased recognition.

can be seen in Table 1, control subjects provided more $\mathrm{R}$ responses to studied items than did amnesic patients. Also, overall, $\mathrm{R}$ responses to studied (but not to unstudied) items were higher in the low- than in the high-criterion condition. An ANOVA of the proportion of R responses to studied items revealed significant main effects of group $[F(1,33)=16.2, p<.01]$ and instructions $[F(1,33)=4.7$, $p<.05]$. Although the effect of instructions was more pronounced in the control group than in the amnesic group, the group $\times$ instructions interaction failed to reach significance $[F(1,33)=1.9, p>.17]$. An analysis of the proportion of $\mathrm{R}$ responses to unstudied items revealed no significant effects (all $F_{\mathrm{s}}<1$ ). An ANOVA of $\mathrm{R}$ discriminability $\left(d^{\prime}\right)$ scores revealed significant effects of group $[F(1,33)=17.3, p<.01]$ and instructions $[F(1,33)=5.7, p<.05]$, but no group $\times$ instructions interaction $(F<1)$.

$\mathrm{K}$ judgments did not vary appreciably across groups or instructions, and there were no significant effects in either the hit rate (all $F_{\mathrm{s}}<1.2, p \mathrm{~s}>.27$ ) or the false alarm rate (all $F_{\mathrm{S}}<1$ ). To obtain a measure of familiarity, we applied the IRK procedure and calculated for both hits and false alarms the proportion of $\mathrm{K}$ responses as a function of the proportion of responses that were not given an $\mathrm{R}$ response (see Table 1). ${ }^{1}$ There were no significant effects in either the analysis of hits (all $F_{\mathrm{S}}<2.6, p \mathrm{~s}>.11$ ), or false alarms (all $F_{\mathrm{s}}<1.1, p \mathrm{~s}>.30$ ). Analysis of $d^{\prime}$ scores derived from this data revealed a significant main effect of group $[F(1,32)=4.8, p<.05]$, indicating that familiarity-based discriminability was greater in control subjects than in amnesics.

These results provide no evidence for the notion that changes in response criterion affect amnesics' recognition accuracy. However, these findings need to be interpreted cautiously, because our manipulation failed to affect overall performance either in amnesic patients or in control subjects.

Despite the fact that manipulating the response criterion did not affect the overall hit and false alarm rates of either group, this manipulation was not without effect, because it increased the discriminability of $\mathrm{R}$ responses. This result argues against the notion that $\mathrm{R}$ responses reflect an all-or-none process. Rather, it suggests that $\mathrm{R}$ responses are susceptible to decision strategies, and that the lenient task instructions may have led participants to adjust the amount of contextual or associative information that they felt they needed to be recollected to give $\mathrm{R}$ responses ${ }^{2}$ (see also Perfect, Mayes, Downes, \& Van Eijk, 1996).

\section{EXPERIMENT 2}

Because a direct manipulation of response criterion failed to affect the overall proportion of items endorsed by control subjects, in the present experiment we attempted to induce changes in response criterion indirectly, by manipulating the information provided to participants about the alleged proportion of study items in the recognition test. Several studies in normal individuals have demonstrated that this manipulation affects response criterion, with participants endorsing more targets and distractors in the condition in which they are given higher base-rate information (Hirshman \& Henzler, 1998; Strack $\&$ Forster, 1995). In the present experiment, which was modeled after Hirshman and Henzler (1998), we assessed recognition in two conditions in which subjects were told that $30 \%$ or $70 \%$ of the items were targets. As in Experiment 1 , our goal was to examine whether a manipulation that affects response criterion in controls can enhance amnesics' recognition accuracy. "Remember" and "know" (R and K) judgments were again collected as a means of elucidating the nature of amnesics' enhanced performance.

\section{Method}

Participants. Fifteen amnesic patients (11 males, 4 females) with an etiology of alcoholic Korsakoff 's syndrome $(n=5)$, anoxia $(n=8)$, encephalitis $(n=1)$, or bithalamic stroke $(n=1)$ participated in the experiment. The amnesic group had a mean age of 59.3 years and a mean education of 14.7 years. Their intellectual functioning was in the average range, as indicated by a mean WAIS-R verbal 
Table 2

Proportion of Studied and Unstudied Words Endorsed as Old, and $d^{\prime}$ Scores, in the Different Criterion Conditions of Experiment 2

\begin{tabular}{|c|c|c|c|c|c|c|c|c|}
\hline & \multicolumn{2}{|c|}{ Overall } & \multicolumn{2}{|c|}{$\mathrm{R}$} & \multicolumn{2}{|c|}{$\mathrm{K}$} & \multicolumn{2}{|c|}{ Familiarity } \\
\hline & Amnesics & Controls & Amnesics & Controls & Amnesics & Controls & Amnesics & Controls \\
\hline \multicolumn{9}{|l|}{$\overline{\text { Studied }}$} \\
\hline $30 \%$ Criterion & .47 & .67 & .10 & .50 & .38 & .18 & .43 & .44 \\
\hline $70 \%$ Criterion & .66 & .78 & .22 & .60 & .44 & .19 & .55 & .48 \\
\hline \multicolumn{9}{|l|}{ Unstudied } \\
\hline $30 \%$ Criterion & .24 & .05 & .03 & .01 & .22 & .04 & .23 & .04 \\
\hline $70 \%$ Criterion & .28 & .15 & .07 & .03 & .21 & .10 & .22 & .11 \\
\hline \multicolumn{9}{|l|}{$d^{\prime}$} \\
\hline $30 \%$ Criterion & .72 & 2.33 & .47 & 2.13 & & & .64 & 1.72 \\
\hline $70 \%$ Criterion & 1.02 & 2.14 & .69 & 2.21 & & & .99 & 1.56 \\
\hline
\end{tabular}

Note-Overall endorsement rates are broken down into $\mathrm{R}$ and $\mathrm{K}$ responses. R responses provide a measure of recollection. Familiarity estimates are based on IRK scores $(\mathrm{K} / 1-\mathrm{R})$ and provide a measure of familiaritybased recognition.

IQ of 100.1. On the WMS-R, the amnesic patients obtained a mean General Memory index of 74.7, Delayed Recall index of 58.7, and Attention-Concentration index of 101.4.

The control group consisted of 8 individuals with a history of alcoholism ( 7 males, 1 female) and 10 healthy adults without a history of alcoholism (4 males, 6 females). Alcoholic controls had abstained from alcohol for at least 1 month prior to participation in the experiment. The control group was matched to the amnesic patients in terms of age $(M=61.2$ years), education $(M=14.3$ years $)$, and verbal IQ $(M=105.7)$.

Materials. One hundred twenty low-frequency nouns $(M=30.5)$ served as stimuli (Francis \& Kučera, 1982). Two lists were constructed, each consisting of two sets of 30 items matched for frequency. For each list, one of the two sets served as targets and the other served as distractors for the recognition task. Assignment of lists to instruction conditions, as well as assignment of item sets as targets, was counterbalanced across participants.

Procedure. The participants were tested in two sessions separated by 1 week. The procedure during each study phase was identical to that in Experiment 1. During the test phase, the participants again made yes/no recognition judgments. In the $30 \%$ base-rate condition, they were told that 3 out of every 10 words would be words from the study list. In the $70 \%$ base-rate condition, they were told that 7 out of every 10 words would be from the study list. The participants were told to keep this information in mind while making their judgments. In reality, 5 out of every 10 words $(50 \%)$ had appeared on the study list in both conditions.

$\mathrm{R}$ and $\mathrm{K}$ responses were collected for each endorsed item and were explained as in Experiment 1.

\section{Results and Discussion}

The results of the alcoholic and nonalcoholic amnesic subgroups and control subgroups were combined, because there were no significant differences as a function of alcohol history.

Overall recognition. Table 2 presents the proportion of "yes" responses to studied and unstudied items given by amnesic patients and control subjects in the $30 \%$ and $70 \%$ base-rate conditions. In contrast to the results of Experiment 1, the proportion of hits and false alarms was affected by instructions, with both groups showing a greater proportion of "yes" responses in the $70 \%$ than in the $30 \%$ base-rate condition. An ANOVA of the propor- tion of hits revealed significant effects of group $[F(1,31)=$ $8.8, p<.01]$ and instructions $[F(1,31)=21.9, p<.01]$. The group $\times$ instructions interaction was not significant $[F(1,31)=1.4, p>.24]$. An ANOVA of the proportion of false alarms also revealed significant effects of group $[F(1,31)=15.4, p<.01]$ and instructions $[F(1,31)=6.8$, $p<.05]$, but no group $\times$ instructions interaction $[F(1,31)=1.21, p>.28]$. Although both groups endorsed more items in the $70 \%$ base-rate condition, inspection of $d^{\prime}$ scores indicates that the effect of instructions differed across the two groups, since only amnesics' discriminability increased in the 70\% base-rate condition. An ANOVA of $d^{\prime}$ scores confirmed these findings: There was a main effect of group $[F(1,31)=28.0, p<.01]$ and a significant group $\times$ instructions interaction $[F(1,31)=5.0, p<$ $.05]$. Consistent with our hypothesis, the instructions had a significant effect on the performance of amnesics $[t(14)=2.0, p<.05$, one-tailed], but not controls $[t(17)=$ $-1.19, p>.25]$.

Remember-know responses. The performance of amnesics and controls was subdivided into $\mathrm{R}$ and $\mathrm{K}$ responses; data from 1 amnesic patient and 1 control participant were eliminated because these individuals were unable to follow the remember-know instructions. Control subjects provided a greater proportion of $\mathrm{R}$ responses to studied items than did amnesic patients. Also, R responses in both groups were greater in the $70 \%$ than in the $30 \%$ base-rate condition, and this effect was more pronounced for studied than for unstudied items. An ANOVA of the proportion of $\mathrm{R}$ responses to studied items revealed significant effects of group $[F(1,29)=$ $35.1, p<.01]$ and instructions $[F(1,29)=7.6, p<.05]$. The group $\times$ instructions interaction was nonsignificant $(F<1)$. An analysis of the proportion of $\mathrm{R}$ responses to unstudied items revealed a marginal effect of group $[F(1,29)=3.5, p<.08]$ and a significant effect of instructions $[F(1,29)=7.6, p<.01]$. Again, the group $\times$ instructions interaction was nonsignificant $[F(1,29)=$ $2.0, p>.17]$. Analysis of $d^{\prime}$ scores based on $\mathrm{R}$ responses 
revealed a significant effect of group $[F(1,29)=52.5, p<$ $.01]$. Neither the effect of instructions $[F(1,29)=1.9$, $p>.18$ ] nor the group $\times$ instruction interaction $(F<1)$ was significant, suggesting that $\mathrm{R}$ discriminability did not differ as a function of base-rate condition in either group.

The pattern of $\mathrm{K}$ responses was rather different. Amnesics provided more $\mathrm{K}$ responses than did controls to both studied and unstudied items. Instructions had relatively small effects, but these tended to be opposite in the two groups: $\mathrm{K}$ responses to studied items were affected by instructions more in amnesics than in controls, whereas $\mathrm{K}$ responses to unstudied items were affected by instructions more in controls than in amnesics. An ANOVA of the proportion of $\mathrm{K}$ responses to studied items revealed only a main effect of group $[F(1,29)=19.4, p<.01]$. Neither the effect of instructions nor the group $\times$ instructions interaction were significant (both $F \mathrm{~s}<1$ ). An ANOVA of the proportion of $\mathrm{K}$ responses to unstudied items revealed a main effect of group $[F(1,29)=18.1, p<.01]$, a nonsignificant effect of instructions $[F(1,29)=1.4, p>$ $.25]$, and a marginal group $\times$ instructions interaction $[F(1,29)=3.1, p<.09]$.

Estimates of familiarity were obtained by applying the IRK procedure to both hits and false alarms. As can be seen in Table 2, familiarity-based responses to studied items were affected by instructions in both groups, but familiarity-based responses to unstudied items were affected by instructions primarily in the control group. As a consequence, there was a net increase in familiarity-based discriminability in amnesics, but not in controls. Analysis of familiarity-based responses to studied items revealed a main effect of instructions $[F(1,29)=4.5, p<.05]$. Neither the effect of group nor the group $\times$ instructions interaction was significant (both $F_{\mathrm{s}}<1.1, p \mathrm{~s}>.30$ ). Analysis of familiarity-based responses to unstudied items revealed significant effects of group $[F(1,29)=18.3, p<$ $.01]$. Neither the effect of instructions $[F(1,29)=2.1$, $p>.16]$ nor the group $\times$ instructions interaction $[F(1,29)=2.6, p>.12]$ reached significance. An ANOVA of $d^{\prime}$ scores derived from this data revealed a significant effect of group $[F(1,29)=8.5, p<.01]$, but no effect of instructions $(F<1)$. The group $\times$ instructions interaction failed to reach significance $[F(1,29)=2.8$, $p<.11]$. However, familiarity-based $d^{\prime}$ scores in amnesia were higher in the $70 \%$ than in the $30 \%$ base-rate condition $[t(13)=1.9, p<.05$, one-tailed], consistent with the a priori hypothesis that enhanced discriminability in amnesia would be associated with enhanced familiarity.

The base-rate manipulation was successful in affecting the performance of control participants, as controls endorsed more items in the $70 \%$ than in the $30 \%$ condition. Most importantly, while this manipulation affected control subjects' response bias, it enhanced amnesics' discriminability. Using a different experimental manipulation, these results extend the findings of Dorfman et al. (1995) to patients with global amnesia.

Our findings also provide support for Dorfman et al.'s (1995) hypothesis that enhanced recognition accuracy in amnesic patients reflects an increased contribution of fa- miliarity to performance. The base-rate manipulation did not affect amnesics' recollection-based discriminability, as measured by the proportion of $\mathrm{R}$ responses. However, using know (IRK) judgments to estimate the contribution of familiarity, we found that amnesics' familiarity-based discriminability was greater in the $70 \%$ than in the $30 \%$ base-rate condition.

\section{GENERAL DISCUSSION}

In two experiments, we examined the effects of instructions designed to relax participants' response criterion on recognition accuracy in patients with global amnesia. In the first experiment, direct instructions to respond more leniently failed to influence amnesics' recognition, but the manipulation also failed to affect the performance of control subjects. In the second experiment, varying information about the alleged proportion of targets on a recognition test successfully affected the overall endorsement rate in the control group. Conditions that made control subjects relax their response criterion led to enhanced recognition accuracy in patients with global amnesia. Thus, improved discriminability as a function of instructions appears not to be limited to patients with ECT-induced amnesia.

The results of Experiment 2 are inconsistent with the findings of Reber and Squire (1999), who found no differences in amnesics' accuracy as a function of response criterion. Although the reasons for this inconsistency are unclear, two factors deserve consideration. In their first experiment, the two recognition tests were given in immediate succession, a procedural feature that may have made it difficult for amnesic patients to change their approach to the task. In Experiment 3 of their study (as in Experiment 1 of the present study), the experimental manipulation had only a marginal effect on overall endorsement rates in amnesic patients and had no effect on overall endorsement rates of controls. Taken together with the failure to affect response criterion in Experiment 1 of the present study, these results suggest that the experimental manipulation was relatively weak.

Amnesics' enhanced discriminability in the $70 \%$ baserate condition of Experiment 2 was associated with an increased reliance on familiarity as indexed by IRK, because a larger proportion of items that were not labeled $\mathrm{R}$ received a $\mathrm{K}$ response (rather than being rejected). Dorfman and colleagues (Dorfman et al., 1995) also proposed that familiarity was responsible for the enhanced recognition observed in ECT patients in a low-criterion condition, although their study provided only indirect evidence for this assertion. They demonstrated that priming on a word stem completion task was normal in their patients, and they assumed that this priming was the source of enhanced familiarity. The relationship between priming and familiarity, however, remains poorly understood. Several findings suggest that familiarity in recognition memory can be dissociated from the processes that mediate perceptual priming (Stark \& Squire, 2000; Wagner \& Gabrieli, 1998; Wagner, Gabrieli, \& Verfaellie, 1997), but there is no ev- 
idence for a dissociation between familiarity-based recognition and conceptual priming. It is plausible, therefore, that conceptual priming is the source of the familiarity that contributes to recognition memory.

The finding that amnesic patients in the present study used familiarity information in the $70 \%$ base-rate condition that they did not use in the $30 \%$ base-rate condition raises the possibility that amnesics' use of such information has been underestimated in previous studies. Furthermore, it suggests that the use of familiarity as a basis for recognition depends not only on the availability of such information, but also on participants' willingness to make use of it. Since amnesic patients are aware of their memory deficits, they may be reluctant to attribute the experience of familiarity to a prior encounter. It may not be sufficient simply to tell patients to base their judgments on familiarity (e.g., Reber \& Squire, 1999); rather, it may be necessary to provide them with a reason to attribute feelings of familiarity to the study list. The knowledge that $70 \%$ of the test items were previously studied may have provided a plausible source for patients' experience of familiarity, thus leading to an increased likelihood of attributing that familiarity to the study list, and an enhancement in recognition memory performance.

\section{REFERENCES}

Aggleton, J. P., \& Shaw, C. (1996). Amnesia and recognition memory: A re-analysis of psychometric data. Neuropsychologia, 34, 51-62.

Donaldson, W. (1996). The role of decision processes in remembering and knowing. Memory \& Cognition, 24, 523-533.

Dorfman, J., Kinlstrom, J. F., Cork, R. C., \& Misiaszek, J. (1995). Priming and recognition in ECT-induced amnesia. Psychonomic Bulletin \& Review, 2, 244-248.

Francis, W. N., \& KuČERA, H. (1982). Frequency analysis of English usage: Lexicon and grammar. Boston: Houghton Mifflin.

GARDINER, J. M. (1988). Functional aspects of recollective experience. Memory \& Cognition, 16, 309-313.

Gardiner, J. M., \& Parkin, A. J. (1990). Attention and recollective experience in recognition memory. Memory \& Cognition, 18, 579-583.

Hirshman, E., \& Henzler, A. (1998). The role of decision processes in conscious recollection. Psychological Science, 9, 61-64.

Hirshman, E., \& Master, S. (1997). Modeling the conscious correlates of recognition memory: Reflections on the remember-know paradigm. Memory \& Cognition, 25, 345-351.

JACOBY, L. L., \& Dallas, M. (1981). On the relationship between autobiographical memory and perceptual learning. Journal of Experimental Psychology: General, 110, 306-340.

JAcoby, L. L., Yonelinas, A. P., \& Jennings, J. M. (1997). The relation between conscious and unconscious (automatic) influences: A declaration of independence. In J. D. Cohen \& J. W. Schooler (Eds.), Scientific approaches to the question of consciousness (pp. 13-47). Hillsdale, NJ: Erlbaum.
Knowlton, B., \& Seuire, L. (1995). Remembering and knowing: Two different expressions of declarative memory. Journal of Experimental Psychology: Learning, Memory, \& Cognition, 21, 699-710.

Mandler, G. (1980). Recognizing: The judgement of previous occurrence. Psychological Review, 87, 252-271.

Perfect, T. J., Mayes, A. R, Downes, J. J., \& Van Eijk, R. (1996). Does context discriminate recollection from familiarity in recognition memory. Quarterly Journal of Experimental Psychology, 49A, 797-813.

Reber, P. J., \& SQuire, L. R. (1999). Relaxing decision criteria does not improve recognition memory in amnesic patients. Memory \& Cognition, 27, 501-511.

Schacter, D. L., Verfaellie, M., \& Pradere, D. (1996). The neuropsychology of memory illusions: False recall and recognition in amnesic patients. Journal of Memory \& Language, 35, 319-344.

Stark, C. E. L., \& SQuire, L. R. (2000). Recognition memory and familiarity judgments in severe amnesia: No evidence for a contribution of repetition priming. Behavioral Neuroscience, 114, 459-467.

STRACK, F., \& ForSTER, J. (1995). Reporting recollective experiences: Direct access to memory systems? Psychological Science, 6, 352-358.

Tulving, E. (1985). Memory and consciousness. Canadian Psychology, 26, 1-12.

Verfaellie, M., \& Treadwell, J. (1993). Status of recognition memory in amnesia. Neuropsychology, 7, 5-13.

WAgner, A. D., \& Gabrieli, J. D. E. (1998). On the relationship between recognition familiarity and perceptual fluency: Evidence for distinct mnemonic processes. Acta Psychologica, 98, 211-230.

Wagner, A. D., Gabrieli, J. D. E., \& Verfaellie, M. (1997). Dissociations between familiarity processes in explicit recognition and implicit perceptual memory. Journal of Experimental Psychology: Learning, Memory, \& Cognition, 23, 305-323.

WeCHSLER, D. (1981). Wechsler Adult Intelligence Scale-Revised. New York: Psychological Corporation.

WeChSLER, D. (1987). Wechsler Memory Scale-Revised. San Antonio, TX: Psychological Corporation.

YonelinAs, A. P., \& JACOBY, L. L. (1995). The relation between remembering and knowing as bases for recognition: Effects of size congruency. Journal of Memory \& Language, 34, 622-643.

Yonelinas, A. P., Kroll, N. E. A., Dobbins, I., Lazzara, M., \& KNight, R. T. (1998). Recollection and familiarity deficits in amnesia: Convergence of remember-know, process dissociation, and receiver operating characteristic data. Neuropsychology, 12, 323-339.

\section{NOTES}

1. One control subject whose $p(\mathrm{R})=1$ was excluded from this analysis because the contribution of familiarity was undefined.

2. Since the results of Experiment 1 suggest that participants merely changed their criterion for assigning $\mathrm{R}$ versus $\mathrm{K}$, the question arises whether $\mathrm{R}$ and $\mathrm{K}$ judgments should be thought of as reflecting a single continuum of trace strength (Donaldson, 1996; Hirshman \& Master, 1997). A strong prediction of the single trace model is that discriminability based on R judgments $\left(A_{\mathrm{R}}^{\prime}\right)$ and overall discriminability $\left(A_{\mathrm{R}}^{\prime}+\right.$ $\mathrm{K})$ should be equivalent (Donaldson, 1996). In contrast to this prediction, $A_{\mathrm{R}}^{\prime}+\mathrm{K}$ was greater than $A_{\mathrm{R}}^{\prime}$ for patients [.74 vs. .66, $F(1,16)=30.4, p<$ $.01]$ as well as for controls [.86 vs. $.81, F(1,17)=12.4, p<.01]$. Further evidence against a trace strength notion comes from Experiment 2, in which a base-rate manipulation led to an increase in familiarity-based recognition, but not recollection-based recognition. 


\section{APPENDIX}

Amnesic Patients' Overall $d^{\prime}$ Scores

Under the Criterion Conditions of Experiment 1

\begin{tabular}{llll}
\hline & & \multicolumn{2}{c}{$d^{\prime}$ Score } \\
\cline { 3 - 4 } Patient & \multicolumn{1}{c}{ Etiology } & High & Low \\
\hline P.B. & Korsakoff & 0.66 & 0.51 \\
R.D. & Korsakoff & 0.91 & 1.3 \\
R.G. & Korsakoff & 0.73 & 0.78 \\
W.K. & Korsakoff & 1.14 & 1.25 \\
R.M. & Korsakoff & 0.57 & 0.36 \\
J.G. & Korsakoff & 0.61 & 0.51 \\
W.R. & Korsakoff & 1.03 & 1.72 \\
W.S. & Korsakoff & 1.45 & 0.76 \\
A.B. & Anoxia & 0.97 & 1.07 \\
P.D. & Anoxia & -0.08 & 0.54 \\
D.F. & Anoxia & 1.06 & 0.91 \\
R.L. & Anoxia & 1.63 & 1.56 \\
J.M. & Anoxia & 0.79 & 1.17 \\
P.S. & Anoxia & 0.59 & 1.04 \\
W.S. & Anoxia & 2.03 & 2.14 \\
C.C. & Anoxia & 0.15 & 0.51 \\
S.S. & Encephalitis & 0.28 & 0.24 \\
C.W. & Bithalamic stroke & 1.56 & 0.61
\end{tabular}

Amnesic Patients' Overall $d^{\prime}$ Scores

Under the Criterion Conditions of Experiment 2

\begin{tabular}{llll}
\hline & & \multicolumn{2}{c}{$d^{\prime}$ Score } \\
\cline { 3 - 4 } Patient & \multicolumn{1}{c}{ Etiology } & $30 \%$ & $70 \%$ \\
\hline P.B. & Korsakoff & 1.22 & 1.08 \\
R.D. & Korsakoff & 0.64 & 0.83 \\
R.G. & Korsakoff & 0.85 & 1.36 \\
W.K. & Korsakoff & 0.58 & 1.41 \\
R.M. & Korsakoff & 0.79 & 0.60 \\
A.B. & Anoxia & 0.86 & 1.23 \\
P.D. & Anoxia & 0.16 & 0.69 \\
D.F. & Anoxia & 0.36 & 0.60 \\
R.L. & Anoxia & 1.37 & 1.08 \\
J.M. & Anoxia & 0.33 & 0.59 \\
D.S. & Anoxia & 0.11 & 1.61 \\
P.S. & Anoxia & 1.31 & 0.60 \\
W.S. & Anoxia & 1.3 & 0.99 \\
S.S. & Encephalitis & 0.24 & 1.11 \\
C.W. & Bithalamic stroke & 0.67 & 1.51 \\
\hline
\end{tabular}

(Manuscript received June 15, 2000;

revision accepted for publication November 20, 2000.) 